\title{
Detection of clade types (clades I and II) within Anopheles funestus sensu stricto by the hydrolysis probe analysis (Taqman assay)
}

\author{
Kwang Shik Choi ${ }^{1,2}$, Maureen Coetzee ${ }^{1,2^{*}}$ and Lizette L Koekemoer ${ }^{1,2}$
}

\begin{abstract}
Background: Recent studies presented two clades (clades I and II) within the major malaria vector, Anopheles funestus s.s. on the mitochondrial DNA. We describe a hydrolysis probe analysis (Taqman assay) method for the rapid identification of these two clades.

Findings: A total of 53 An. funestus s.s. from Malawi and Mozambique were tested for detection of clade types using the hydrolysis probe analysis. Results were compared to DNA sequence analysis to verify the accuracy of the probes Taqman assay for this vector species. Analysis using the hydrolysis probe revealed that there were 21 individuals from Malawi and 13 individuals from Mozambique for clade I, and 19 individuals from Mozambique for clade II. The results were consistent with the results of DNA sequences. A field sample from northern Zambia revealed the presence of both clade types.

Conclusion: A diagnostic method using the hydrolysis probe analysis was developed to identify clade types within An. funestus s.s. This assay will be useful for screening clade types of field-collected An. funestus specimens accurately and efficiently in malaria vector research and control studies.
\end{abstract}

Keywords: Anopheles funestus, Clades, Malawi, Mozambique

\section{Findings}

\section{Background}

One of the major African malaria vectors, Anopheles funestus Giles belongs to a group of at least eleven species, all of which are morphologically similar at the adult stage [1-5]. It is widespread in sub-Saharan Africa including Madagascar [1,6] and is the most anthropophilic and endophilic species of the group [1]. Michel et al. [7] reported that the population structure of An. funestus s.s. based on NADH Dehydrogenase subunit 5 (ND5) data revealed two cryptic subdivisions, clade I widespread throughout Africa and clade II known only from Mozambique and Madagascar. Choi et al. [8] also reported that An. funestus s.s. from Mozambique

\footnotetext{
* Correspondence: maureenc@nicd.ac.za

${ }^{1}$ Malaria Entomology Research Unit, School of Pathology, Faculty of Health Sciences, University of the Witwatersrand, Johannesburg, South Africa ${ }^{2}$ Centre for Opportunistic, Tropical and Hospital Infections, National Institute for Communicable Diseases, Division of the National Health Laboratory Service, Johannesburg, South Africa
}

has two clades based on the DNA sequence analysis of ND5 and Cytochrome Oxidase I (COI).

The hydrolysis probe analysis combines PCR amplification reaction and visualisation into a single step. This method uses oligonucleotide probes dual-labelling with a fluorescent reporter dye and a quencher molecule. The probe-specific product is amplified and this leads to cleavage of the probe, generating an increase in reporter fluorescence. The reporter dye is released away from the quencher and cleavage of allele-specific probes can be observed in a single PCR by using different reporter dyes $[9,10]$. The hydrolysis probe analysis can be considered to be one of the best methods with regard to specificity and sensitivity for detecting one substitution such as the knockdown resistance $(k d r)$ mutations $[10,11]$.

In this article, we report on the use of a hydrolysis probe assay (Taqman assay) that is able to accurately and rapidly identify the two clade types of An. funestus s.s. 


\begin{tabular}{|c|c|c|c|}
\hline & 22 & & 69 \\
\hline An. funestus s.s. & TATCССССТTТАТСA & TCAGGAATTGCTCATGCT & GGTGCTTCAGTTGAT \\
\hline Clade I (Mal) & & & $\ldots{ }^{c}{ }_{T}$. \\
\hline Clade I (Moz) & $\ldots \ldots \ldots \ldots{ }^{A_{a}}$ & $\ldots \ldots$ & $\ldots{ }_{T}^{A} \ldots$ \\
\hline Clade II (Moz) & $\ldots \ldots \ldots \mathrm{C}$. & $\ldots \ldots \ldots, c \ldots$ & $\ldots c_{\tau}^{c} \ldots \ldots$ \\
\hline
\end{tabular}

Figure 1 Alignment from $3^{\prime}$ to $5^{\prime}$ end of the $\mathrm{COI}$ target region for probes. The alignment of An. funestus for the comparison were originated from GenBank (access No. AY423059). Mal and Moz represent Malawi and Mozambique respectively. Dots represent identity with respect to the An. funestus sequences. ${ }^{\mathrm{A}}{ }_{\mathrm{G}}{ }^{\mathrm{C}} \mathrm{T}_{\mathrm{T}}$ and ${ }^{\mathrm{A}} \mathrm{T}$ indicate polymorphic positions. The square indicates the sequences of the probes for clades I and II.

\section{a}

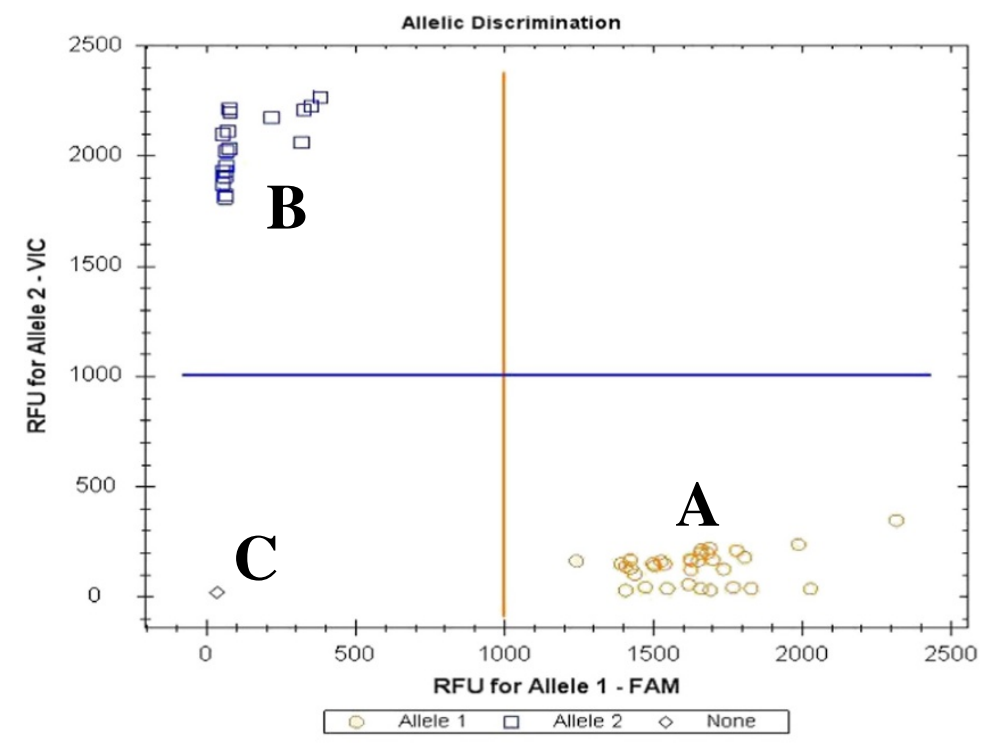

$\mathrm{b}$

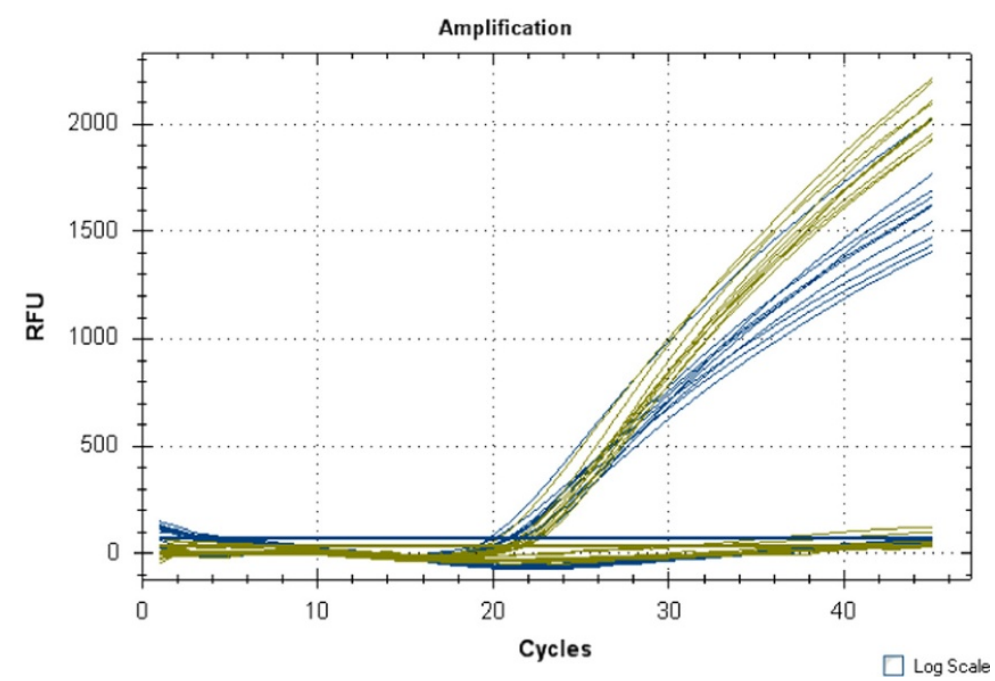

Figure 2 Hydrolysis probe analysis fluorescence results for clades I and II of An. funestus s.s. from Malawi and Mozambique. Scatter plot analysis (a) of A) clade I; B) clade II; C) negative control and quantitative peaks (b). Blue peaks are clade I and yellow peaks are clade II. 

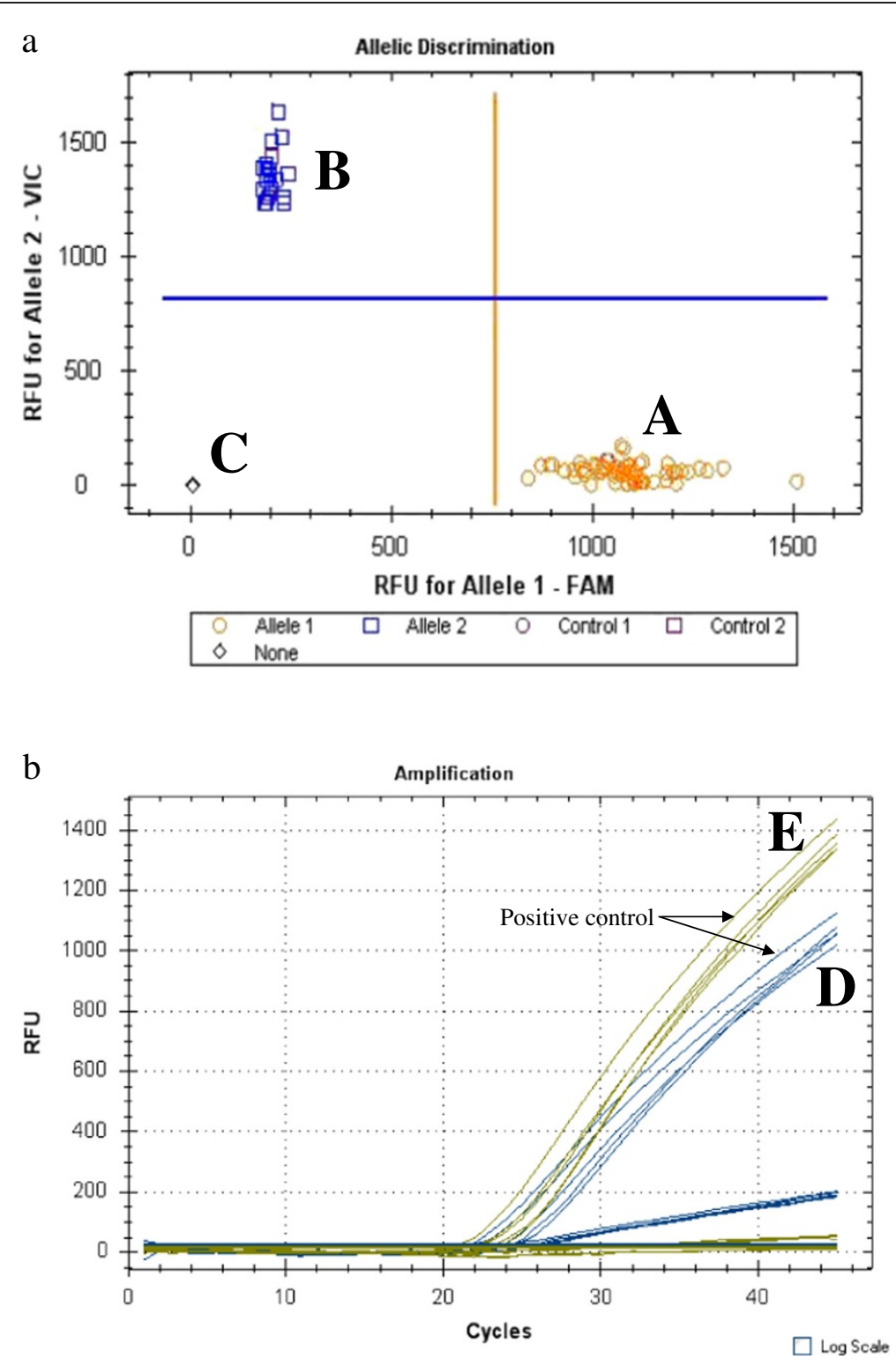

Figure 3 Hydrolysis probe analysis fluorescence results for clades I and II of An. funestus s.s. from Zambia. Scatter plot analysis (a) and quantitative peaks (b) of A) clade I; B) clade II; C) negative control. Blue peaks are clade I and yellow peaks are clade II. Positive controls (arrows) from the Figure 2 experiment are $\mathbf{D}$ ) clade I and E) clade II.

\section{Methods}

\section{Mosquito sample collection and identification}

Specimens were collected resting inside houses from Karonga $\left(10^{\circ} 19^{\prime} \mathrm{S}, 34^{\circ} 08^{\prime} \mathrm{E}\right)$ and Nkhota kota $\left(12^{\circ} 55^{\prime} \mathrm{S}\right.$, $\left.34^{\circ} 18^{\prime} \mathrm{E}\right)$ in Malawi, Chibuto $\left(24^{\circ} 40^{\prime} \mathrm{S}, 33^{\circ} 33^{\prime} \mathrm{E}\right)$ in Mozambique and Nchelenge $\left(9^{\circ} 21^{\prime} \mathrm{S}, 28^{\circ} 44^{\prime} \mathrm{E}\right)$ in Zambia. The samples were identified using the morphological keys of Gillies and Coetzee [2] and the molecular method of Koekemoer et al. [12]. All DNA samples were extracted from either single mosquitoes or available parts of mosquitoes using the BallingerCrabtree protocol [13]. The DNA templates were resuspended in TE buffer at volumes between $50 \mu \mathrm{L}$ and $100 \mu \mathrm{L}$.

\section{Hydrolysis probe analysis}

PCR was performed using a CFX96 $6^{\text {ma }}$ Real-Time system (Bio-Rad). The primers and probes were designed from COI. The sequence information of COI was presented in Choi et al. [8]. Two standard oligonucleotides (MACROGEN) and two minor groove binding (MGB) probes (Applied Biosystems) were used. Primers Forward (5'- GCA GGA ACA GGA TGA ACA GT -3') and Reverse (5' - GAA ATT CCT GCT AAA TGT AAT 
GAA A -3') were used for binding the flanking region of both clade mutation sites in the COI. The probe clade I (5' - TCA GGA ATT GCT CAT GCT -3') was labelled with 6-FAM for the detection of the clade I and the probe clade II (5' - TCA GGA ATT GCC CAT GCT -3') were labelled with VIC for detection of the clade II. The $20 \mu \mathrm{L}$ PCR reaction contained $1 \mu \mathrm{L}$ of the genomic DNA of an individual mosquito, $10 \mu \mathrm{L}$ of $\mathrm{IQ}^{\mathrm{m}}$ Supermix (Bio-Rad), $0.8 \mu \mathrm{M}$ of each primer and $0.4 \mu \mathrm{M}$ of each probe. The PCR cycling conditions were as follows: an initial denaturation at $95^{\circ} \mathrm{C}$ for 10 minute, followed by 45 cycles of $95^{\circ} \mathrm{C}$ for 10 seconds and $63^{\circ} \mathrm{C}$ for 45 seconds. The increase in FAM and VIC fluorescence was monitored in real time by detecting fluorescence on the yellow channel $(450-490 \mathrm{~nm}$ excitation and 515-530 $\mathrm{nm}$ detection) for clade I and the blue (515-535 $\mathrm{nm}$ excitation and 560-580 $\mathrm{nm}$ detection) for clade II. The Malawi and Mozambique results were confirmed with the sequence results to ensure that experimental error was limited.

\section{Results and discussion}

A total of 53 specimens were used for the assay, 21 from Malawi and 32 from Mozambique. The two specific probes for clades I and II were designed based on one substitution between clades in the partial region of $C O I$ (Figure 1). The first specific probe for the clade I allele was labelled with FAM and the second specific probe for the clade II allele was labelled with VIC. All 21 An. funestus individuals from Malawi were clade I type while 13 and 19 individuals from Mozambique were clades I and II respectively (Figure 2). The results from the hydrolysis probe analysis in this study were $100 \%$ consistent with the results from the DNA sequencing. Subsequently, a field sample of 78 An. funestus individuals from Nchelenge in northern Zambia became available and were successfully analysed as clades I $(\mathrm{n}=59)$ and II $(\mathrm{n}=19)$, using the above sequenced specimens as positive controls (Figure 3 ).

This assay will save time when routinely identifying collections of wild mosquitoes belonging to this important malaria vector species. Although this method is expensive compared to the PCR method, it is much more accurate than PCR, cheaper than DNA sequence analysis, and avoids the potential safety hazard presented by the use of ethidium bromide [10]. Similar results were reported by Bass et al. [10] who developed the hydrolysis probe analysis (Taqman assay) for detection of the $k d r$ mutations in Anopheles gambiae based on one nucleotide substitution, concluding that it is the most specific and sensitive method compared with seven other diagnostic assays including the PCR method.

At present we do not know if the various molecular and chromosomal forms in An. funestus are associated with insecticide resistance or vector competence, nor whether "intergrades" can be found in different populations. It is also not clear whether the RFLP types [14], the clades [7] and the chromosomal forms [15] in $A n$. funestus are themselves in any way associated. Since $A n$. funestus is such an important malaria vector in Africa, it is vital that we understand the basic underlying genetics of the species as this will allow us to better comprehend its role in malaria transmission and the evolution and spread of insecticide resistance.

\section{Conclusion}

The application of the assay described here is expected to greatly improve the efficiency of screening largescale field-collected samples of An. funestus s.s. for clades I and II. Hence, this assay could help elucidate the role that each clade is playing in malaria transmission and whether there is any difference in insecticide resistance frequencies.

\section{Competing interests}

The authors declare no competing interests.

\section{Authors' contributions}

KSC designed the study, developed the new hydrolysis probe analysis and drafted the manuscript. LLK and MC assisted with analysis of the data and helped draft the manuscript. All authors read and approved the final manuscript.

\section{Acknowledgements}

This work received financial aid from the Hillel Friedland fellowship and the University of the Witwatersrand. MC was supported by a DST/NRF South African Research Chair Initiative grant.

Received: 28 March 2013 Accepted: 4 June 2013

Published: 12 June 2013

\section{References}

1. Gillies MT, de Meillon B: The Anophelinae of Africa South of the Sahara. Johannesburg, South: Publications of the South African Institute for Medical Research; 1968.

2. Gillies MT, Coetzee M: A Supplement to the Anophelinae of Africa South of the Sahara (Afrotropical Region). Johannesburg, South Africa: Publications of the South African Institute for Medical Research; 1987.

3. Couhet A, Simard F, Toto J-C, Kengne P, Coetzee M, Fontenille D: Species identification within the Anopheles funestus group of malaria vectors in Cameroon and evidence for a new species. Am J Trop Med Hyg 2003, 69:200-205.

4. Harbach RE: The classification of genus Anopheles (Diptera: Culicidae): a working hypothesis of phylogenetic relationships. Bull Entomol Res 2004, 94:537-553.

5. Spillings BL, Brooke BD, Koekemoer LL, Chiphwanya J, Coetzee M, Hunt RH: A new species concealed by Anopheles funestus Giles, a major malaria vector in Africa. Am J Trop Med Hyg 2009, 81:510-515.

6. Mouchet J, Manguin S, Sircoulon J, Laventure S, Faye O, Onapa AW, Carnevale P, Julvez J, Fontenille D: Evolution of malaria in Africa for the past 40 years: impact of climatic and human factors. J Am Mosq Control Assoc 1998, 14:121-130.

7. Michel AP, Ingrasci MJ, Schemerhorn BJ, Kern M, Le Goff G, Coetzee M, Elissa N, Fontenille D, Vulule J, Lehmann T, Sagnon N, Costantini C, Besansky $\mathrm{NJ}$ : Rangewide population genetic structure of the African malaria vector Anopheles funestus. Mol Ecol 2005, 14:4235-4248.

8. Choi KS, Koekemoer LL, Coetzee M: Population genetic structure of the major malaria vector An. funestus s.s. and allied species in southern Africa. Parasit Vectors 2012, 5:283. 
9. Livak KJ: Allelic discrimination using fluorogenic probes and the 5' nuclease assay. Genetic Anal 1999, 14:143-149.

10. Bass C, Nikou D, Donnelly MJ, Williamson MS, Ranson H, Ball A, Vontas J, Field L: Detection of knockdown resistance ( $k d r)$ mutations in Anopheles gambiae: a comparison of two new high-throughput assays with existing methods. Malaria J 2007, 6:111.

11. Choi KS, Spillings BL, Coetzee M, Hunt RH, Koekemoer LL: A comparison of DNA sequencing and the hydrolysis probe analysis (TaqMan assay) for knockdown resistance $(k d r)$ mutations in Anopheles gambiae from the Republic of the Congo. Malaria J 2010, 9:278.

12. Koekemoer LL, Kamau L, Hunt RH, Coetzee M: A cocktail polymerase chain reaction assay to identify members of the Anopheles funestus (Diptera: Culicidae) group. Am J Trop Med Hyg 2002, 66:804-811.

13. Ballinger-Crabtree ME, Black WC, Miller BR: Use of genetic polymorphisms detected by the Random-Amplified Polymorphic DNA Polymerase Chain Reaction (RAPD-PCR) for differentiation and identification of Aedes aegypti subspecies and populations. Am J Trop Med Hyg 1992, 47:893-901.

14. Koekemoer LL, Kamau L, Garros C, Manguin S, Hunt RH, Coetzee M: Impact of the Rift Valley on Restriction Fragment Length Polymorphism Typing of the Major African Malaria Vector Anopheles funestus (Diptera: Culicidae). J Med Entomol 2006, 43:1178-1184.

15. Costantini C, Sagnon NF, Ilboudo-Sanogo E, Coluzzi M, Boccolini D: Chromosomal and bionomic heterogeneities suggest incipient speciation in Anopheles funestus from Burkina Faso. Parassitologia 1999, 41:595-611.

doi:10.1186/1756-3305-6-173

Cite this article as: Choi et al:: Detection of clade types (clades I and II) within Anopheles funestus sensu stricto by the hydrolysis probe analysis (Taqman assay). Parasites \& Vectors 2013 6:173.

\section{Submit your next manuscript to BioMed Central and take full advantage of:}

- Convenient online submission

- Thorough peer review

- No space constraints or color figure charges

- Immediate publication on acceptance

- Inclusion in PubMed, CAS, Scopus and Google Scholar

- Research which is freely available for redistribution

Submit your manuscript at www.biomedcentral.com/submit
() Biomed Central 